
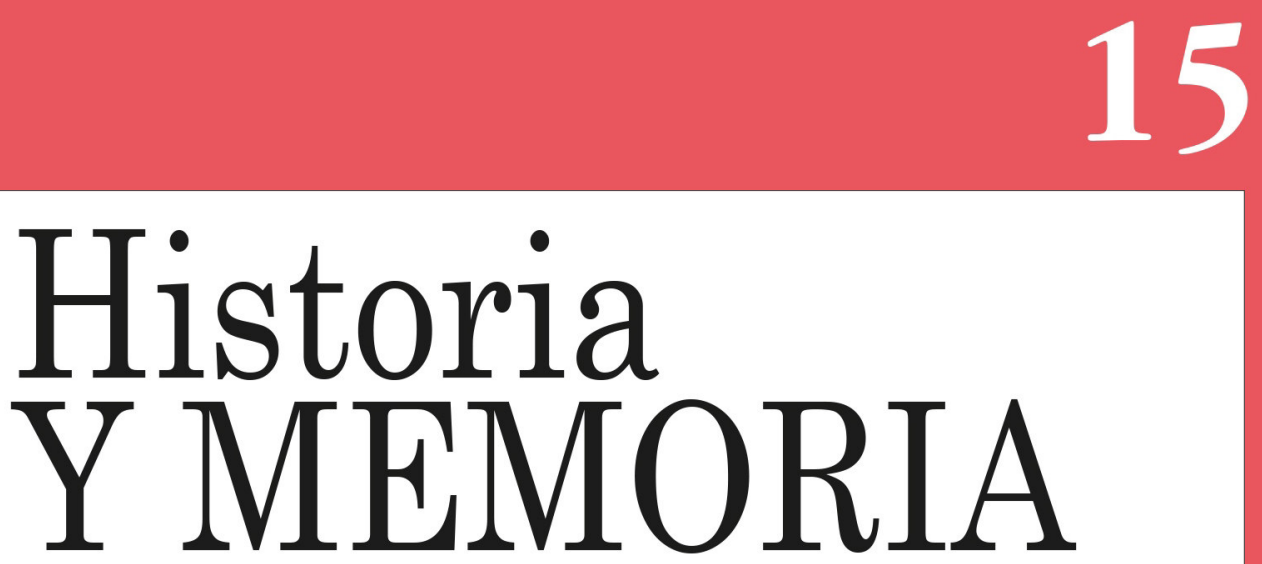

ISSN: 2027-5137 Julio - Diciembre, Año 2017 - Tunja, Colombia

Manifestaciones artísticas y culturales afrocolombianas. Una aproximación al caso de Girardota (Antioquia)

https://doi.org/10.19053/20275137.n15.2017.4926

América Larraín González

orcid.org/0000-0002-5783-2815

Pedro José Madrid Garcés orcid.org/0000-0002-3848-2880

Páginas: 107-135

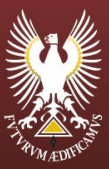




\title{
Manifestaciones artísticas y culturales afrocolombianas. Una aproximación al caso de Girardota (Antioquia)*
}

\author{
América Larraín González ${ }^{1}$ \\ Universidad Nacional de Colombia - Sede Medellín \\ Pedro José Madrid Garcés ${ }^{2}$ \\ Universidad Nacional de Colombia - Sede Medellín
}

Recepción: 30/06/2016

Evaluación: 19/03/2017

Aprobación: 10/04/2017

Artículo de Investigación e Innovación.

https://doi.org/10.19053/20275137.n15.2017.4926

\section{Resumen}

Tomando como punto de partida una etnografía realizada entre 2015 y 2016 , este artículo ofrece una descripción de los elementos que componen el escenario de las manifestaciones artísticas y culturales de una comunidad afrodescendiente en el municipio de Girardota, Antioquia.

Por este camino, llegamos a la conclusión de que hay un lazo indisociable entre la participación de la comunidad en escenarios políticos y de organización comunitaria, y el

* Este artículo es producto de la investigación, «La danza y el sainete, una aproximación a las manifestaciones culturales Afro en el municipio de Girardota - Antioquia", financiada por Vicerrectoría de la Universidad Nacional -Sede Medellín-, en el marco de la convocatoria de Proyectos para el fortalecimiento de la Investigación, la Creación y la Innovación en Posgrados de la Universidad Nacional de Colombia 2013-2015.

1 Doctora en Antropología Social (Universidad Federal de Santa Catarina, Brasil). Vinculada al grupo de investigación: «Historia, trabajo, sociedad y cultura» (UNAL Medellín). Líneas de investigación: Estudios sobre el patrimonio cultural; Dimensiones políticas del arte y la cultura; Antropología del arte. Publicaciones recientes: «Bailar fútbol reflexiones sobre el cuerpo y la nación en Colombia», Boletín de Antropología 30, $\mathrm{n}^{\circ} 50$ (2015): 191-207. $\square$ aylarraingo@unal.edu.co (iD orcid. org/0000-0002-5783-2815

2 Magister en Estudios Políticos (Universidad Nacional de Colombia, sede Medellín). \ pjmadridg@unal.edu.co (iD orcid.org/0000-0002-3848-2880 
carácter étnico que se atribuye a sus manifestaciones artísticas y culturales.

Aquí privilegiamos un enfoque que entiende dichas manifestaciones como un vehículo para acceder a reflexiones históricas, sociales y políticas, exponiendo cómo, tras la Constitución de 1991 y con la implementación del discurso del multiculturalismo en Colombia, la población de ascendencia africana reformula su identidad étnica para establecer un vínculo diferencial con su historia esclava y servil.

Palabras clave: afrocolombianos, Girardota - Antioquia, manifestaciones artísticas, identidad étnica.

\section{Artistic and Cultural Afro-Colombian Manifestations. An Approximation to the Case of Girardota (Antioquia, Colombia)}

\section{Summary}

Taking an ethnography developed between 2015 and 2016 as a starting point, this article offers a description of the elements that compose the backdrop for the artistic and cultural manifestations of an Afro-descendant community in the municipality of Girardota, Antioquia.

In this way, we conclude that there is an inseparable bond between this community's participation in political and community organization scenarios, and the ethnical character attributed to their artistic and cultural manifestations.

We priviledge a focus that understands these manisfestations as a vehicle for historical, social and political reflection. This implies exposing how, after the Constitution of 1991 and with the implementation of the multicultural discourse in Colombia, population of African descent reformulates its ethnical identity to establish a differential relation with regards to its history of slavery and servitude.

Key Words: Afro-Colombians, Girardota - Antioquia (Colombia), Artistic Manifestations, Ethnic Identity. 


\section{Manifestations artistiques et culturelles afro- colombiennes. Une approche au cas de Girardota (Antioquia)}

\section{Résumé}

En prenant comme point de départ une ethnographie entreprise entre 2015 et 2016, cet article offre une description des éléments qui composent la scène des manifestations artistiques et culturelles d'une communauté afro appartenant à la municipalité de Girardota (Département d'Antioquia).

Cette approche nous permet de conclure qu'il existe un lien indissociable entre la participation de la communauté dans la vie politique et l'organisation communautaire et le caractère ethnique que l'on attribue à ses manifestations artistiques et culturelles.

Nous privilégions ici une approche qui conçoit ces manifestations comme une voie d'accès à des réflexions historiques, sociales et politiques. D'ailleurs, c'est dans le cadre de la Constitution de 1991 et de la mise en pratique du discours du multiculturalisme en Colombie que les populations afro reformulent leur identité ethnique afin d'établir un lien différentiel avec leur passé d'esclavage et de servitude.

Mots-clés: Afro-colombiens, Giradota-Antioquia, manifestations artistiques, identité ethnique.

\section{Introducción}

Las manifestaciones artísticas y culturales, han sido para las ciencias humanas y sociales un valioso foco de observación, análisis y descripción, así como un lugar privilegiado para comprender las dinámicas históricas, políticas, económicas y culturales. Todo aquello que soporta y promueve la existencia de tales prácticas, está conformado por dimensiones estéticas, que a su vez están relacionadas con lo político o lo histórico, -y en esa medida-, son espacios destacados para conocer y 
comprender los elementos que dan sentido a la vida social de los sujetos y a las comunidades que estos integran ${ }^{3}$.

En esa medida, nos interesa en esta reflexión establecer una aproximación a las manifestaciones artísticas y culturales que desempeñan un importante rol en los "procesos de identificación" y cohesión social ${ }^{4}$, moldeando la existencia de un grupo que se piensa y autodenomina afrodescendiente en el contexto colombiano contemporáneo ${ }^{5}$.

De esta forma, nuestra reflexión no pretende ser un enfoque historiográfico exhaustivo, sino mas bien, una aproximación etnográfica con una revisión bibliográfica de fuentes históricas, que permita tejer lazos y establecer conexiones entre las fuentes oficiales de la historia local de esclavos de origen africano en el Valle de Aburrá, y las versiones y voces de quienes hoy en día se reivindican como afrodescendientes antioqueños.

Para el caso que nos ocupa, es importante mencionar la ausencia en materia de estudios históricos locales, la falta de documentación archivística y la gran dificultad para acceder a la historia oral de sus actuales habitantes. En este escenario, encontramos que fuentes no convencionales, como las expresiones artísticas y culturales, fueron vehículos muy eficaces para acceder a relatos y anécdotas de la historia local, ofreciendo información sobre los diferentes fenómenos que han incidido en la región, moldeando sus expresiones artísticas y culturales. Para estudiar dichas prácticas culturales fue necesario auscultar fragmentos de relatos que se han hecho difusos con el paso del tiempo; confrontar fuentes escritas y simultáneamente, reflexionar sobre la historia y la actualidad

3 Félix Guattari y Suely Rolnik, Micropolitica: Cartografías del deseo (Buenos Aires: Tinta Limón, 2013), 9.

4 Jean Wainer, La mundialización de la cultura (Barcelona: Editorial Gedisa, 2000), 12 .

5 Es importante anotar, que aquí hacemos uso de la categoría afro como concepto nativo, es decir, como el marcador étnico diferencial que una población rural del Valle de Aburrá, en Antioquia, utiliza para autodenominarse. Por tal razón no entraremos a discutir o profundizar el concepto en sí mismo, sino que lo usaremos en relación con los relatos y discursos de los interlocutores de la investigación. 
de las comunidades que hacen posible la existencia de tales manifestaciones artísticas y culturales hoy en día.

Aquí nos concentraremos en el caso de la música, la danza y el sainete ${ }^{6}$, entendiéndolas como un conjunto estético integrado que para ser comprendido, precisa ser visto de forma total. Estas tres manifestaciones son producto del proceso de apropiación y transformación, que durante la colonia hizo la población esclava de prácticas artísticas de ascendencia europea, que con el paso del tiempo han entrado a conformar el acervo cultural de la población negra en el municipio de Girardota.

En esta búsqueda, uno de los aspectos más llamativos fue encontrar que dichas expresiones, además de ser un vehículo para reflexiones sobre el orden social e histórico configuraron el ámbito festivo municipal y caracterizaron a la comunidad negra en el municipio ${ }^{7}$, algo paradójico y que podría pensarse como una contradicción, puesto que se trata de un grupo que reivindica su identidad afro, mediante la práctica de música, danza y teatro de origen español. Sin embargo, es pertinente mencionar que el caso girardotano no es excepción nacional, pues en el contexto colombiano existen otros grupos de ascendencia africana que no comparten el imaginario de lo afro, asociado exclusivamente a una musicalidad de percusión, y que por el contrario, interpretan instrumentos de cuerdas. Tal es el caso de los raizales insulares en San Andrés y Providencia con sus polcas y chotis, y de las comunidades negras del norte del Cauca, reconocidos por la interpretación de los violines.

Dichas expresiones, tras la promulgación de la Constitución de 1991 y del desarrollo de políticas de diversidad, han posibilitado la revitalización de comunidades

$6 \quad$ Expresión artística teatral para animar la vida de la colonia, caracterizada por una búsqueda escénica donde se incorporara la música, la danza y el verso. En: Ximena Cuervo y Edwin Arias, "Imágenes Culturales a través del juego escénico: Sainete» (Tesis de pregrado: Universidad de Antioquia, 1989), 23.

7 En: Municipio de Girardota, «Fiestas y celebraciones», acceso el 22 de julio de 2016 http://www.girardota.gov.co/MiMunicipio/Paginas/Fiestas-y-Celebraciones. aspx 
negras, mediante la visibilización y reconocimiento de sus expresiones culturales. De esta forma, las prácticas culturales y artísticas ocupan un importante rol en el discurso de la nación pluriétnica y multicultural, sirviendo tanto como expresión de la diversidad nacional a nivel local y como puente con la historia y el pasado colonial.

\section{Metodología del proceso}

Para realizar este estudio partimos de una etnografía efectuada en la región citada, donde privilegiamos el trabajo de campo, las entrevistas y diálogos informales con la población local, así como la observación de presentaciones, ensayos y ensambles de las manifestaciones artísticas en eventos públicos. Se realizaron visitas y entrevistas a saineteros, músicos líderes comunitarios, integrantes del grupo de danzas y habitantes de la vereda, así como a directivos de la administración municipal. Todo esto, para obtener información y conocer de primera mano las manifestaciones artísticas y a quienes las ejecutan, al igual que identificar las relaciones con lo público y su incidencia en las agendas administrativas locales. Dentro de esta etapa inicial de observación, también se hizo un acompañamiento de dicha comunidad en los ejercicios de consulta previa, proyectos interinstitucionales, eventos del Consejo Comunitario Afrodescendiente, participación política y presentaciones en entidades del sector público.

Luego de efectuar el trabajo de campo, se dio paso a la segunda etapa: el estudio de fuentes escritas y audiovisuales sobre las manifestaciones artísticas y la comunidad negra en el municipio de Girardota, con el objetivo de nutrir y evaluar los datos obtenidos en campo y construir una disertación entre las manifestaciones artísticas identificadas, la herencia afro, su historia territorial y las transformaciones producto de la apropiación cultural, como escenario base de reflexión respecto al sujeto étnico y su posterior despliegue en asuntos públicos.

Finalmente, se realizó una revisión bibliográfica especializada con los grandes temas que aborda la 
investigación: lo étnico, el multiculturalismo, el patrimonio, lo político, la identidad, el arte y la cultura; buscando estructurar una aproximación a la historia de lo afro y sus expresiones artísticas en Girardota. De esta forma, a través del estudio de las manifestaciones artísticas, encontramos un camino para establecer una reconstrucción histórica de los relatos locales sobre ser afro en Antioquia, así como de los cambios políticos ocurridos como resultado del reconocimiento oficial y la reformulación de la identidad étnica en comunidades afrodescendientes.

\section{El pasado colonial: de Hatogrande a Girardota}

En la subregión Norte del Valle de Aburrá, se encuentra ubicado en la margen oriental del río Medellín, el municipio de Girardota, el cual se llamó en otra época Hatogrande, para connotar el gran potencial de recursos naturales, agrícolas y pecuarios que disponía el territorio en mención ${ }^{8}$.

Los primeros pobladores de los que hay registro, fueron los indígenas Nutabes antes de la conquista Española. La zona norte del Valle de Aburra fue conocida desde finales del siglo XVI como las "Tierras del Río Abajo» siendo su primer propietario el Gobernador Don Gaspar de Rodas.

En 1598, el dominio legal de las tierras del «Río Abajo» (Actuales municipios de Girardota y Copacabana) fue transmitido a Alonso de Rodas Carrojal, mediante decreto de la misma anualidad. Dicho territorio estaba caracterizado por bastos recursos naturales, con diversas especies de madera, que sirvieron para abastecer la construcción de haciendas paneleras y hatos ganaderos. Tal proceso fue transformando el bosque nativo que rápidamente cedió paso a unidades productivas del sector pecuario ${ }^{9}$.

8 Elkin Meneses, Ruth Meneses y Mario Sierra, Tierra prolífica Tierra sagrada (Medellín: Instituto para el desarrollo de Antioquia Idea, 2006), 32-33.

9 Carlos Correa, «De Hatogrande a Girardota» (Tesis de pregrado, Universidad de Antioquia, 2002), 40. 
En el año de 1620, colonos llegados de la ciudad de Antioquia, levantaron el primer caserío en el paraje denominado San Diego. Dicho proceso de colonización estuvo acompañado por un proceso de migración hacia esa zona, en la que la limitación de recursos obligó a los colonos a implementar actividades diferentes a la búsqueda de oro, tales como la siembra de caña de azúcar y la cría de ganado, utilizando mano de obra esclava ${ }^{10}$.

El proceso de colonización se fortaleció con la independencia de Copacabana en el año de 1833, mediante Decreto del Gobernador Juan de Dios Aránzazu, a través del cual se le dio autonomía administrativa y parroquial ${ }^{11}$. Para abril de 1912 el terreno de Hato-grande recibió el nombre de Girardot, en memoria del Coronel Atanasio Girardot, mediante ordenanza del 29 de abril de tal año. Este nombre generó discordia entre las corrientes políticas de la población, por lo que posteriormente, mediante acuerdo del concejo municipal, en abril de 1913, el municipio de Girardot se llamó Girardota, nombre que lleva hasta hoy ${ }^{12}$.

El desarrollo socioeconómico e histórico del municipio de Girardota, ha tenido como base modelos de producción pecuaria y agrícola a través de grandes haciendas, al igual que el establecimiento de trapiches, los cuales datan de 1790, y se consolidan como producción representativa del municipio para el año $1860^{13}$. En un escenario donde la hacienda era la principal unidad productiva, cobró vital importancia el modo de producción esclavista ${ }^{14}$, fomentando la traída de esclavos negros al territorio para solventar las necesidades productivas del lugar.

10 Correa, «De Hatogrande...», 40-41.

11 Gustavo López, Héctor Rendón y Fred Danilo Palacio, Atardecer en San Andrés. Música tradicional de Girardota, Antioquia (Medellín: Universidad de Antioquia, 2006), 2 .

12 Jorge Rodríguez, Maizopolis: monografías de los distritos antioqueños (Medellín: El Correo Liberal, 1915), 69.

13 Meneses, Meneses y Sierra, Tierra prolífica..., 42-43.

14 López, Rendón y Palacio, Atardecer en San Andrés..., 2. 
Durante el proceso de ocupación del territorio, fueron cuatro los grandes núcleos poblacionales: San Diego, San Esteban, El Totumo y San Andrés. Este último, se caracterizó por tener un grupo poblacional diferente a los demás asentamientos del municipio, ya que con características particulares, al ser un territorio enmontado, permitía a los esclavos negros cimarronear y escapar de las haciendas localizadas al borde de las vegas del río, hacia la parte alta de la montaña para establecerse, conformando grupos de familias negras representativas poblacionalmente en la parte alta de la vereda ${ }^{15}$.

\subsection{Vereda San Andrés y población afro}

Ubicada al margen izquierdo del Río Medellín, 3 kilómetros al nororiente de la cabecera municipal, la vereda San Andrés fue el lugar donde se establecieron grandes haciendas en función de la actividad económica que se desarrollaba en ellas: la minería y la explotación de caña de azúcar, realizadas por esclavos. La época a la que nos remitimos aquí, corresponde a la fundación del distrito de Hatogrande, donde se instalaron colonos en 1620, concretamente en el paraje conocido como San Diego ${ }^{16}$.

La fuerza de trabajo más empleada en las haciendas establecidas al norte del Valle de Aburrá y primordialmente en Hatogrande (nombre inicial del municipio de Girardota), estuvo representada por negros, quienes habían sido traídos al territorio para suplir la mano de obra indígena. Con relación al comercio de esclavos, los registros muestran que fueron introducidos al sistema hacendario en el municipio de Girardota, 103 africanos en 1665, procedentes de Guinea, Angola, Congo y Cabo Verde. De estos 103 esclavos negros, buena parte se ubicó en lo que es hoy la vereda San Andrés, siendo la base de la unidad productiva minera y hacendaria ${ }^{17}$.

15 Meneses, Meneses y Sierra, Tierra prolifica..., 31-32.

16 Correa, «De Hatogrande...», 39-40.

17 Correa, «De Hatogrande...», 39-40. 
Los esclavos negros juntaron sus propios bailes y costumbres con las tradiciones españolas, dando origen a manifestaciones autóctonas de los habitantes de la vereda San Andrés. De esta forma, la hacienda como núcleo de creación fue importante para criollos, mestizos, mulatos y esclavos, pues esta configuró un centro de actividades no solo productivas y económicas como la agricultura, la ganadería o los trapiches, sino también culturales y artísticas como las artesanías, la música y los bailes.

Con el inicio del movimiento antiesclavista en el mundo, a comienzos del siglo XIX, y concretamente para el caso colombiano, cerca de 1851 (cuando finalmente se concretó el decreto de libertad de esclavos), en la región se inició un proceso de fugas y escapes constantes de las haciendas. Muchos se asentaron en la parte alta de la montaña de la vereda San Andrés, conformando un núcleo de población negra en los territorios más enmontados del sector. Fue así, como esta población, una vez manumitida, se quedó en el territorio que ya conocía y que había ayudado a constituir. Posteriormente, junto con algunas familias blancas, mestizas y mulatas, conformaron y dieron forma al territorio que actualmente conocemos como vereda San Andrés.

Esta vereda, caracterizada por un fuerte arraigo religioso, resultado del proceso de evangelización católica del sistema colonial, siempre tuvo en las festividades y celebraciones sagradas un importante lugar para las intervenciones artísticas, pues era justamente en primeras comuniones, bautizos y romerías ${ }^{18}$, que la música se tocaba y se bailaba. En dichos eventos, importantes reuniones comunitarias, era clave la figura del sacerdote, pues era él quien las autorizaba e instalaba ${ }^{19}$.

18 Fiesta popular que con meriendas, bailes, etc., se celebra en el campo inmediato a alguna ermita o santuario el día de la festividad religiosa del lugar. En: Diccionario de la lengua española, "Romería», acceso el 10 de junio de 2016, http://dle.rae. es/?id=WeRtrBl.

19 Sergio Henao, Los Santuarios y las romerías. Monografía histórica sobre peregrinaciones y santuarios en los municipios de Girardota, Angostura, Copacabana, Sabaneta y Guarne (Medellín: Instituto de Cultura y Patrimonio de Antioquia, 2015), 12. 
Con el transcurrir del tiempo, la economía de la vereda San Andrés pasó de ser exclusiva mente agrícola a diversificarse en actividades como la agricultura y la construcción, esta última especialmente a partir de la puesta en marcha del ferrocarril de Antioquia, que generó empleo y contacto con pobladores de diversas regiones. Con el establecimiento de la Estación San Andrés, que se localizaba en la parte baja de la vereda, hubo mejores ingresos económicos para la población local, al tiempo en que se dio un importante contacto con otras expresiones culturales, particularmente musicales, que con el tiempo entraron a hacer parte de las tradiciones de San Andrés ${ }^{20}$.

Posteriormente, a mediados del siglo XX, en pleno auge del desarrollo industrial del municipio de Girardota, el sector laboral se transforma nuevamente. Como consecuencia de ello, los pobladores rurales se insertan en las cadenas de producción de las industrias asentadas en las vegas del río Medellín que cruzan la municipalidad. Dicha situación se mantiene en la actualidad.

Es de anotar que gran parte de la información relacionada con la historia y las manifestaciones artísticas y culturales de la vereda no se encuentra depositada en textos, pues lo que allí predomina, es una tradición oral ampliamente difundida, que recae especialmente en las personas más ancianas. Con frecuencia la comunidad busca a «los viejos» para tratar estos temas de interés histórico.

\subsection{Expresiones artísticas y culturales afro en Girardota}

La fiesta como escenario de encuentro, permitió a la población de la vereda San Andrés integrar a mestizos, afro-descendientes y criollos. El resultado de dichas fiestas, denominadas por «los viejos», «bailes Bravos» o «bailes de Calle», fue el nicho donde se gestaron manifestaciones artísticas como la música,

20 Arnobia Foronda, Tradición oral sobre la historia de la vereda San Andrés Girardota - Antioquia (Girardota: Consejo Comunitario de la Vereda San Andrés Corantioquia, 2002), 26. 
la danza, las trovas, la poesía y en especial los sainetes ${ }^{21}$. Estos últimos condensan el proceso de mestizaje cultural acaecido en la región, pues es allí donde se evidencia con mayor claridad la presencia de elementos de origen europeo que fueron apropiados y transformados por la población afro a lo largo de los años.

Según apuntan diversas fuentes, los esclavos de las familias hacendarias de ascendencia española, espiaban las fiestas y eventos culturales que dichas familias hacían a puerta cerrada. Allí, habrían extraído y adaptado fragmentos de música y danza, que posteriormente interpretaban en sus propias fiestas de modo jocoso, ridiculizando a sus amos ${ }^{22}$.

Las festividades, permitían a los pobladores afrodescendientes integrarse como comunidad, establecer lazos y conexiones entre sus familias, para sobrellevar el complejo contexto de la esclavitud y posteriormente la servilidad. Una posible explicación para el sentido de arraigo y cohesión de esta comunidad, se encuentra en la resistencia contra la sociedad «criolla» de Girardota, que organizaron los negros libres después de la abolición de la esclavitud y hasta muy avanzado el siglo $\mathrm{XX}^{23}$.

Como consecuencia de tal resistencia y de las tensiones sociales y políticas derivadas, la vereda San Andrés experimentó cierto aislamiento o repliegue, del que da cuenta la tradición oral: «ellos [los negros] no iban mucho al pueblo [...] porque era que la gente de las partes urbanas no los

$21 \quad$ El término baile bravo estaba designando entonces en un fenómeno social - cultural que congregaba varios elementos y que fue común en varias localidades del Departamento de Antioquia, en el caso particular de San Andrés tiene una significación social étnica (afirmación como grupo humano negro), política (en cuanto expresión de intereses propios de un grupo humano) y ritual comunitario, por sus nexos con expresiones mágico-religiosas. En: López, Rendón y Palacio, Atardecer en San Andrés..., 6.

22 Corantioquia, Hijos de la Rima: una voz bien hablada cuenta la historia del sainete del Consejo Comunitario Afrodescendiente de la Vereda San Andrés (Medellín: Corantioquia, 2011), 26.

23 López, Rendón y Palacio, Atardecer en San Andrés..., 3. 
estimaban mucho, entonces ellos [los negros] se mantenían retirados de ellos [los blancos] aquí en San Andrés» ${ }^{24}$.

Como resultado del aislamiento, la comunidad afrodescendiente gestó con autonomía sus manifestaciones artísticas, que eran realizadas principalmente en sus encuentros de fin de semana, donde predominaban la danza, la música de cuerda y los sainetes. Entrado el siglo XX, la tradición oral destaca que ensayaban los sábados en las tardes, luego de efectuar su jornada laboral, para refinar, componer y mejorar sus interpretaciones en los «bailes de Calle». Asimismo, en estos encuentros, conversaban de los problemas de la vereda y de las necesidades de la comunidad, programando convites para la construcción y reparación de vías y casas, al igual que el trabajo conjunto en la producción de panela y ganadería.

Fue tal la importancia de este ambiente festivo, que la arquitectura de las viviendas en la vereda, en especial, las afrodescendientes, se transformó a través del tiempo, privilegiando un lugar común para las presentaciones artísticas. Según Gómez y Toro «para el año de 1850, los asentamientos ya giraban en torno a un espacio central comunal, donde se desarrollaban actividades de tipo colectivo» ${ }^{25}$. Dicho espacio central, se erigía como un lugar público donde los afrodescendientes recreaban su cultura y cultivaban sus danzas.

Para 1930, luego de variados cambios a nivel arquitectónico y de propiedad sobre las tierras, los servicios sanitarios se integran a la estructura de la vivienda, dando paso a una zona social frontal más amplia para las actividades culturales y las celebraciones de tipo colectivo, dentro de las cuales, según la tradición oral, se efectuaban serenatas, danzas y sainetes, al igual que fiestas acompañadas de música de cuerda.

24 López, Rendón y Palacio, Atardecer en San Andrés..., 4.

25 John Gómez y Jairo Toro, «Vereda de San Andrés Municipio de Girardota, una propuesta de vivienda para una cultura» (Tesis de Grado: Universidad de Nacional de Colombia, 1997), 89-90. 
Es pertinente resaltar que lo festivo desempeñó un rol crucial en la vida social de esta comunidad con remanente colonial, pues permitió construir un escenario en el que se integraron diferentes grupos, permitiendo la convivencia a pesar de las barreras de clase y étnicas, en pro del esparcimiento. En el caso de San Andrés, lo festivo aún tiene tal importancia, que sin su existencia, las manifestaciones artísticas y culturales serían precarias y en determinados casos inexistentes, al igual que los lazos comunitarios y las relaciones de vecindad, según manifiestan distintos moradores de la vereda ${ }^{26}$.

\section{Expresiones artísticas: apropiaciones, transformaciones y continuidades}

Los ya mencionados «bailes Bravos» o «bailes de Calle», cuna del sainete y de otras manifestaciones artísticas locales, fueron resultado del contacto cultural de los grupos afrodescendientes con las manifestaciones de origen español. En el contexto de producción y explotación colonial, los esclavos tomaron y adaptaron elementos estéticos de las manifestaciones culturales dominantes, que acabaron incorporando a sus propias prácticas.

Si bien sabemos que la población afro fue desposeída de todos sus bienes materiales, no ocurrió lo mismo con buena parte de su bagaje cultural inmaterial ${ }^{27}$, y en esa medida, lo que existe hoy en la vereda San Andrés en Girardota, es resultado del proceso de transformaciones históricas y culturales, propio de la interacción social en prácticamente cualquier escenario.

Es deresaltar, quetodas estas prácticas secaracterizan por estar en constante transformación, mediante la incorporación de diferentes referentes y elementos musicales, teatrales y dancísticas en sus performances, evidenciando que ninguna cultura puede considerarse estática y que en esa medida, desde el ámbito académico e investigativo, dichos fenómenos

26 Foronda, Tradición oral..., 14.

27 Maguemati Wabgou, "Herencia Negroafricana en Colombia», Contra Relatos Desde el Sur. Apuntes sobre África y Medio Oriente, n 9 (2012): 102. 
deben ser siempre estudiados a partir de perspectivas que contemplen la continuidad y la transformación ${ }^{28}$; pues de lo contrario, caeríamos en el equívoco de pensar que estamos frente a manifestaciones y prácticas "puras» y «originales». En ese mismo sentido, con relación a los efectos de la Colonia:

[...] En contextos como este, donde la esclavitud fue de gran importancia, los negros debieron adaptarse a un medio cultural extraño en que predominaron las costumbres conservadoras con cierto rezago aristocrático, apoyadas en una fuerte religiosidad católica. Los intercambios e hibridaciones generados en este proceso de adaptación, ayudaron a configurar la variada cultura antioqueña, que trasciende de la reducida versión de carriel, sombrero, ruana y bambuco, para albergar un sin número de expresiones artísticas y culturales bastante peculiares. Dentro de ellas, Girardota cuenta hoy con la música de chirimía, distintas manifestaciones de música campesina y parrandera, amplio repertorio de danzas tradicionales y una perviviente tradición sainetera ${ }^{29}$.

\subsection{Música}

La música vista como texto, permite ahondar en el estudio de los acontecimientos culturales e históricos, reflejados a través de los modos de vida de distintos grupos sociales ${ }^{30}$. En algunas disciplinas académicas como la antropología, esta se ha consolidado como un campo prolífico de estudios, que ha permitido auscultar sentidos y contextos, que se traducen en el conocimiento de los modos de vida tanto de poblaciones indígenas y rurales como de poblaciones modernas y urbanas ${ }^{31}$. Es por ello, que el estudio de las músicas regionales y locales, es una despensa para acceder a contextos que van desde lo

28 Denys Cuche, La notion de culture dans les sciencies sociales (París: Repéresedt, 1996), 16.

29 López, Rendón y Palacio, Atardecer en San Andrés..., 6.

30 Shirli Gilbert, «Music as Historical Source: Social History and Musical Texts», International Review of the Aesthetics and Sociology of Music, $\mathrm{n}^{\circ} 36$ (2005): 118.

31 Véase: Allan Merriam, «Ethnomusicology Revisited», Ethnomusicology 2, n 13 (1969): 214. John Blacking. How musical is man? (Washington: University of Washington Press, 1967), 12. John Shepherd, Music as Social Text (Cambridge: Polity Press, 1991) y Rafael Bastos, A festa da Jaguatirica, uma partitura criticointerpretativa (Florianópolis: Editora Universidade Federal de Santa Catarina, 2013). 
histórico (por remitir al pasado), pasan por lo social (definiendo límites o cohesionando) e inciden en lo político (simbólica o explícitamente).

En el caso de la vereda San Andrés, pese a las particularidades históricas de la esclavitud en la región, su música no es la que el imaginario común esperaría de una población afrodescendiente. Es decir, en San Andrés no tenemos la prevalencia de musicalidades vinculadas a la percusión, los bombos o los tambores, sino que encontramos la música andina de cuerdas como género predominante y que identifica las prácticas sonoras locales ${ }^{32}$.

Con relación al repertorio, este es de gran variedad, incluyendo boleros, bambucos, merengues y pasillos, entre otros. Ya respecto a la autoría $u$ originalidad de este tipo de músicas y sus diferentes versiones, es pertinente mencionar que no hay registro de las composiciones, por lo que se apela siempre al rótulo genérico de música andina colombiana. La tradición oral local relata que las composiciones en general eran apropiadas y recompuestas por los habitantes de la vereda, a partir de versiones a las que tenían acceso como consecuencia del flujo de manifestaciones musicales durante la construcción y el funcionamiento del ferrocarril. En ese sentido es complejo en la región hablar de autoría o producción autóctona.

De esta forma, siguiendo a Domínguez «las diferentes realizaciones pueden ubicarse siempre en algún lugar de la línea de continuidad que existe entre los polos de la creación individual y del anonimato o creación colectiva ${ }^{33}$. Por lo que, como lo señala la autora referida, se concluye que la condición de originalidad de la producción musical en la vereda San

32 Carlos Orlas, y otros, Identidad y memoria. Rastros de la tradición oral en la Vereda San Andrés (Medellín: Corporación el balcón - Gobernación de Antioquia Instituto de Patrimonio y Cultura, 2014), 16.

33 María Domínguez, «Versiones, apropiación e intermusicalidad en el Río de la Plata (126)", en ANTROPOLOGIA EM PRIMEIRA MÃO, ed. Evelyn Schuler Zea, José Antonio Kelly, Rafael Devos, y Scott Head (Florianópolis: Universidade Federal de Santa Catarina, 2011), 16. 
Andrés, ha cedido frente a la apropiación para el desarrollo de motivos populares y usos festivos a nivel comunitario.

La tradición musical actual de Girardota y de la vereda San Andrés remite a cantos y melodías que se han transmitido de generación en generación, a versiones de músicos jóvenes y adultos que han aprendido al lado de sus parientes, muchos ya desaparecidos, en los que se hace referencia a los «bailes Bravos» $»^{34}$.

Para el caso de San Andrés en Girardota, podemos hablar de la existencia de un entramado artístico danzamúsica-teatro, una vez que, en una sola presentación, estas tres prácticas se integran para formar un complejo sistema de puesta en escena, que hoy en día es la bandera de las festividades del municipio y de su identidad cultural. Dicha interacción entre las diversas manifestaciones artísticas ha sido ampliamente estudiada en el mundo amerindio, y para el caso en análisis, muestra esa relación de amalgama entre la música, el teatro y la danza, que impide pensar una manifestación sin la otra ${ }^{35}$.

En ese sentido, el caso de San Andrés en Girardota, resulta especialmente interesante para pensar, estudiar y analizar las dimensiones históricas, sociales y políticas de las prácticas artísticas y culturales, pues lo que tenemos aquí es una comunidad que se auto reconoce e identifica en la actualidad con "géneros cortesanos que rememoran legados de la época de esclavitud; y repertorios populares que ilustran sobre la transformación del panorama sonoro ante la irrupción de los medios de comunicación y la urbanización creciente de la región ${ }^{36}$. Dicha situación refleja las apropiaciones y transformaciones culturales referidas inicialmente, permitiendo a una comunidad afrodescendiente definirse a través de sus manifestaciones artísticas y culturales, mostrándonos cómo a través de lo estético es posible acceder a la comprensión de las complejas dinámicas sociales.

34 López, Rendón y Palacio, Atardecer en San Andrés..., 6.

35 Bastos, A festa da Jaguatirica..., 55.

36 López, Rendón y Palacio, Atardecer en San Andrés..., 12. 
Concretamente con relación a la música Hernández apunta que:

[...] Si se acepta en principio que el sonido musical es un fenómeno significante, se debe aceptar también que los materiales sonoros están atravesados por relaciones de poder, pues inevitablemente participan en la permanente lucha de significados que constituye lo que entendemos por cultura. Al igual que cualquier otro modo de lenguaje, el sonido musical tiene la capacidad de favorecer unas representaciones de la realidad y cuestionar otras ${ }^{37}$.

\subsection{Danza}

Adela Foronda, líder cultural de la vereda, señala que las danzas en San Andrés, "tienen que ver con un asunto de comunidad y ancestralidad $\iota^{38}$. En este mismo trabajo, menciona que todos los bailes que se realizan en la vereda, fueron rescatados por sus ancestros, haciendo hincapié en los bailes autóctonos como la guabina, la redova, las vueltas, la cumbia, el pasillo y el bambuco.

Es muy común en los discursos nativos encontrar referencias al carácter folclórico asociado a una «herencia genética». Al respecto, Arnobia Foronda (líder cultural y presidenta del Consejo Comunitario Afrodescendiente), indica lo siguiente: "yo creo que eso lo llevamos los negros en la sangre, nuestros ancestros que vinieron de África eran más alegres que nosotros, esa gente era muy rumbera, eso lo llevamos en la sangre» ${ }^{39}$.

$\mathrm{Al}$ igual que la música y el sainete, las danzas hacen parte del complejo proceso de apropiación y transformación de las prácticas artísticas y culturales acaecido en el contexto colonial y republicano. Las festividades de los esclavos eran escenario para todo tipo de danzas, tanto de salón, como bailes

37 Oscar Hernández, «Los mitos de la música nacional. Poder y emoción en las músicas populares colombianas 1930-1960» (Tesis de doctorado, Pontificia Universidad Javeriana, 2014), 14-15.

38 En Orlas, y otros, Identidad y memoria, 3-4.

39 Orlas y otros, Identidad y memoria..., 2. 
Bravos. "Girardota se vio enriquecida por la cultura popular de los bailes y música que nació en la Colonia, de la actividad libre de los esclavos, al reunirse a compartir, tradición que se conserva en sus veredas y de especial manera en la vereda San Andrés» ${ }^{40}$.

Inicialmente no existían grupos de danzas conformados en la vereda, pues en todas las familias se practicaban los bailes y se enseñaban los mismos a través de las fiestas familiares. Para la década de 1970, la familia Foronda y la familia Cadavid, específicamente las mujeres, comenzaron a realizar presentaciones en las reuniones de las juntas de acción comunal de la vereda, conformando oficialmente un grupo de danzas.

Durante el proceso de organización del grupo, entrados ya en la década de 1990, las danzas de la comunidad afrodescendiente de la vereda San Andrés, comenzaron a ser invitadas para eventos en el municipio y en el departamento, donde interactuaron con otras agrupaciones de danza, de las cuales incorporaron trajes y vestidos, como fue el caso de la Chapolera ${ }^{41}$. Anteriormente, las mujeres de la vereda bailaban con una falda negra y una camisa blanca, que eran considerados por los viejos, el traje típico de la vereda.

Llama la atención en este punto, el proceso de construcción de tradiciones, relacionadas con la danza en la vereda San Andrés, pues coincide claramente con lo propuesto por Hobsbawn, en el entendido de que «las tradiciones que parecen o reclaman ser antiguas son a menudo bastante recientes en su origen, y a veces inventadas» ${ }^{42}$. En este caso, la tradición de la danza, que es habitualmente asociada a los «bailes Bravos», en realidad se remite a la instauración de grupos de danzas y a prácticas comunitarias que se rastrean

40 Correa, «De Hatogrande...», 98.

41 Vestido femenino utilizado por mujeres recolectoras de café, con falda larga decorada, cintas de colores o confeccionada con telas estampadas de vivos colores y blusas blancas, de escote cuadrado o redondo con mangas bombachas rematadas.

42 Eric Hobsbawm, La invención de la tradición (Barcelona: Editorial Crítica, 2002), 11. 
en la década de los setentas. Por el contrario, los sainetes son referidos en diversas investigaciones como una manifestación que se remonta a 200 años aproximadamente ${ }^{43}$.

\subsection{Sainete}

De ascendencia europea, el sainete fue introducido por los españoles como una expresión artística teatral durante la colonia. Se trata de una transformación del teatro español durante el denominado siglo de oro (finales del XVI y comienzos del XVII). El sainete se caracterizó por una búsqueda escénica donde se incorporara la música, la danza y el verso, convirtiéndose en la máxima expresión del teatro popular español, pese a las críticas de los movimientos neoclásicos del teatro, al considerarlo un género vulgar ${ }^{44}$.

Según Dowling, el origen del sainete se encuentra en los pasos de Lope de Rueda y con mayor atención en los entremeses de Miguel de Cervantes y Luis de Quiñones ${ }^{45}$. Era, en general, resultado de piezas satíricas y situaciones cómicas. Para el siglo XVIII el término entremés y sainete, eran utilizados indistintamente en el teatro español. El sainete se erige como crítica al afrancesamiento de que padecía el teatro español, «mediante la ridiculización y exaltación de lo popular y formas de vida cotidiana, por lo que se era de agrado a las clases populares» ${ }^{46}$.

Durante el siglo XVII, incluso en el XVIII, surgieron en Colombia diversas manifestaciones teatrales un tanto aisladas como los "chigualos», "alabaos» de la Costa Pacífica; las «mojigangas» en Antioquia, los sainetes populares y demás representaciones como «matachines», "cuadrillas de San Martín» y el «juego de los caballeros», considerados

43 Véase más en: Correa, «De Hatogrande...», 40. Foronda, Tradición oral..., 26. López, Rendón y Palacio, Atardecer en San Andrés..., 3-4. Orlas, y otros, Identidad y memoria..., 6.

44 Cuervo y Arias, «Imágenes Culturales...», 20.

45 John Dowling, Sainetes I: Ramón de la Cruz (Madrid: Castalia Editores, 1981),

15 .

46 Lucy Harney, «Carnival and Critical Reception in the "Sainete" Tradition", MLN 117, n² 2 (2002): 314. 
formas parateatrales cercanas al arte dramático ${ }^{47}$. En el país, en algunas regiones especialmente de Antioquia, el sainete, al igual que en España, se focalizó en ambientes rurales, donde fue adaptado a los contextos campesinos de las diferentes comunidades, generando elementos diferenciadores de la cultura española, cambiando su funcionalidad, en una búsqueda por ridiculizar la marcada tradición aristocrática presente en determinados territorios, entre las familias terratenientes, dueñas de haciendas.

En el caso de la vereda San Andrés, el sainete fue un espacio en el que se ridiculizaban las presentaciones artísticas que se hacían a puerta cerrada por parte de las familias «blancas», según Gilberto Cañas ${ }^{48}$. De esta forma, era una expresión de agrado en las festividades populares de los habitantes de la vereda. En el sainete se forjaron procesos creativos, modificando libretos y componiendo nuevos sainetes para burlarse del canon teatral y aristocrático de las familias asentadas en la parte baja de la vereda.

Los textos de los sainetes son el resultado de la observación de vivencias propias de la comunidad sanandresana a través del tiempo, experiencias vividas por algunos personajes o por algunas familias, o, escenas cotidianas reales recreadas en forma picaresca. Otra característica fundamental del sainete de la vereda San Andrés, es la ejecución de diferentes danzas como bunde, contradanza y la música de parranda. En esa medida, la música que se interpreta, constituye otro elemento que confiere particularidad al sainete de la vereda de San Andrés, en tanto las piezas que se interpretan son de autoría de los músicos que hacen parte del grupo del sainete ${ }^{49}$.

Respecto a la práctica de esta manifestación artística en la vereda San Andrés, una de las más reconocidas líderes del sector, manifiesta:

47 Ver más En: Corantioquia, Hijos de la Rima..., 2011. Cuervo y Arias, «Imágenes Culturales...", 20-21.

48 En Orlas, y otros, Identidad y memoria..., 6.

49 Una recopilación de estas piezas musicales se encuentra En: López, Rendón y Palacio, Atardecer en San Andrés..., 9. 
[...] el sainete, es una de las tradiciones más antiguas que se ha conservado de generación en generación en nuestra comunidad, este ha sido una de las fiestas teatrales y callejera más alegre por sus personajes que son disfrazados de vivos colores. La historia cultural de San Andrés viene de tradiciones atrás, los blancos hacían sus fiestas, pero eran más alegres las de los negros, porque tenían más picante con sus bailes Bravos, sus chistes y sainetes $[\ldots]^{50}$.

Sin duda, actualmente los sainetes son la actividad cultural más importante de esta comunidad, pues constituyen un puente y vínculo directo con su pasado e historia local. En los relatos de los pobladores, todos refieren que los sainetes se presentaban en todo tipo de fiestas de la vereda, en los matrimonios, los bautizos, las visitas de compadres y las fiestas navideñas acompañadas de músicos virtuosos. En esas ocasiones, preparaban licores como la tapetusa y la chicha. «En todas estas fiestas no faltaban cuentos, chistes, las historias antiguas que han sido trasmitidas de generación en generación, como el gritón, la patasola, cargue o alumbre, los compadres, los duendes, la madre monte, la llorona, las brujas y brujos ${ }^{51}$.

El proceso de aprendizaje y transmisión del sainete entre la comunidad afrodescendiente de la vereda San Andrés, fue durante mucho tiempo reservado a los hombres, quienes se reunían secretamente a altas horas de la noche (situación improbable para una mujer en una comunidad campesina extremamente tradicional) a practicar y montar el respectivo sainete. De hecho los compositores y escritores de sainetes, solo entregaban las líneas escritas a mano, de lo que le correspondía a cada personaje, nunca el sainete completo, para evitar que las familias los conociesen antes de las presentaciones y así no perder la gracia en las fiestas ${ }^{52}$.

En esa medida, el sainete se erige como elemento importante de la memoria cultural de esta comunidad, reconocido por su interés histórico, artístico, estético

$50 \quad$ Foronda, Tradición oral..., 80.

51 Foronda, Tradición oral..., 82.

52 Orlas, y otros, Identidad y memoria..., 7. 
en los ámbitos simbólico y musical, que trasciende la representatividad para un grupo cultural (afro) y un territorio (vereda San Andrés), para posicionarse, junto con otras manifestaciones de danza y música, como el evento cultural más importante del ámbito municipal ${ }^{53}$. Dado su reconocimiento y aceptación, han traspasado la frontera municipal, al ser invitados a presentarse en distintos escenarios departamentales y nacionales.

Asimismo, el sainete ha sufrido cambios importantes luego de su apropiación por parte de las entidades estatales, cambios que han generado modificaciones sustanciales en el lugar que ocupa como expresión tradicional de la vereda, al tiempo en que ha propiciado la proliferación de sainetes en la localidad, por publicitar el sainete en ámbitos públicos y privados, convirtiéndolo en una empresa cultural junto a las danzas y a la música.

Esto ha incidido en un proceso de diferenciación y cualificación de la comunidad afrodescendiente de la vereda San Andrés, que ha tenido impacto en la forma de relacionarse con lo estatal. En sus discursos es explícito que no son simples habitantes rurales, sino que se trata de una comunidad donde perviven estos lazos sociales que se expresan mediante sus manifestaciones artísticas, dotando de sentido la herencia de sus ancestros, y que cuenta con reconocimiento oficial, a partir de la constitución de organismos de gestión como el Consejo Comunitario Afrodescendiente.

De esta forma, el sainete es para los habitantes de la vereda San Andrés, un patrimonio con años de tradición, una manifestación que los caracteriza y los identifica en su vida social, que permite la convivencia armónica de sus practicantes al tiempo en que es un espacio integrador. Se trata de una práctica cultural expresada en espectáculos públicos, que se ha trasmitido por generaciones durante casi 200 años.

53 Corantioquia, El sainete está corrido. Estudio para la postulación como patrimonio cultural inmaterial departamental (Medellín: Corporación Gaia, 2011), 112. 


\section{Reflexiones finales}

Estas tres manifestaciones: la música, la danza y el sainete, hacen parte de las variadas expresiones artísticas que caracterizan la vereda San Andrés en el municipio de Girardota y que al mismo tiempo reafirman el carácter étnico afro de los pobladores de dicha comunidad.

El origen de las manifestaciones referidas se encuentra en los procesos de apropiación y transformación cultural a los que se vieron expuestos los pobladores afrodescendientes y mulatos de la vereda, concretamente se originan en las manifestaciones artísticas españolas y las estéticas musicales de los terratenientes hacendarios.

A partir de estos referentes, la población afro se apropió de elementos artísticos disponibles en el contexto de la época, mediante la observación de bailes y teatro español, modificándolos y convirtiéndolos en escenarios para la fiesta y el disfrute de sus comunidades.

Un aspecto llamativo con relación a dicha apropiación, es que tuvo desde sus orígenes un carácter de ridiculización de las figuras autoritarias de la época, siendo también un espacio para la incorporación de acontecimientos triviales de la comunidad, mediante un ejercicio de creatividad y articulación de los distintos elementos estéticos que tenían a disposición y que les eran permitidos, tales como la música, la danza, el teatro y la declamación.

De esta forma, los «bailes Bravos» o «bailes de Calle», se convirtieron en espacio para forjar lazos comunitarios entre los pobladores rurales de la vereda San Andrés, que hoy trascienden la simple identificación de un color de piel. Se trata de un performance, una producción artística, que cuenta con gran refinamiento en sus presentaciones y cuyos ensayos son elementos centrales de la vida social de la vereda.

Por lo tanto, lo que encontramos en la comunidad estudiada, no es un proceso de aculturación, sino 
la resignificación de la existencia de una comunidad afrodescendiente, más allá de su caracterización física, mediante formas de expresarse a través del arte, en un territorio que identifican como propio. En esa medida, no se trata de un color de piel como elemento que determine la adscripción étnica o cultural, sino de las formas de socialización de las que puede disponer un ser humano o una colectividad, generando identificación y sentido de pertenencia.

Este trinomio artístico de los habitantes de la vereda San Andrés, ha sido visto por las entidades estatales a nivel municipal y departamental, con gran agrado para asuntos de representatividad y participación en eventos culturales y festivos, tanto es así, que las fiestas de Girardota, llevan por nombre las fiestas de la danza y el sainete, auspiciando la participación de agrupaciones artísticas de la vereda, en las programaciones culturales anuales.

Por otro lado, queda develada la importancia de formas tradicionales de transmisión de conocimiento artístico y musical, que obedecen también a la inmaterialidad de dichas manifestaciones artísticas, y están atravesadas por la corporeidad $^{54}$, sea por el refinamiento musical para interpretar las diferentes músicas de cuerda, o el disciplinamiento del cuerpo para la expresión de las diferentes danzas, como la preparación para la exposición teatral mediante la introyección de los personajes del sainete y lo que pretenden estos roles evocar ${ }^{55}$.

Estos hechos reflejan la forma en que el cuerpo es socializado ante la comunidad y el mundo, redundando en la reformulación de su identidad y producción de subjetividades a nivel micro, con la construcción de un Yo étnico que se expresa mediante las diferentes prácticas culturales afrodescendientes descritas.

54 Maurice Merleau-Ponty, Fenomenología de la percepción (Barcelona: Ed. Planeta De Agostini, 1993), 90-93.

55 Pierre Bourdieu, Meditaciones Pascalinas (Barcelona: Anagramas, 1999), 148149. 
Con la incursión del multiculturalismo en el campo jurídico político colombiano, se desplegó un escenario de transición hacia lo multicultural. Dentro de esta directriz estatal, se desarrollaron políticas amparadas en el reconocimiento de la diversidad y aportes culturales de grupos étnicos, estructurando y fortaleciendo discursos de reivindicación política, histórica y cultural.

Todo esto, sumado al empoderamiento de dichos discursos y al nuevo margen de maniobra político-jurídico para los grupos étnicos, propicio en comunidades negras como la de la vereda San Andrés, una revitalización de sus manifestaciones artísticas, como medio para adquirir la condición étnica formal ${ }^{56}$, lo que a su vez ha servido de instrumento para propiciar nuevos escenarios de participación y configuración social de la colectividad, mejorando su condición de sujeto político representativo en el Estado.

Esto devela y evidencia, las formas en que se articula el discurso de reivindicación étnica, mediante las manifestaciones artísticas afrodescendientes, para incidir en ámbitos de lo político, al igual que la búsqueda de espacios de acción y participación en lo público. Para el caso de la comunidad negra de la vereda San Andrés, son las manifestaciones artísticas el vehículo que permite acceder a los nuevos escenarios de visibilización, participación y transformación referidos a través del texto, pues sin la existencia de dichas manifestaciones sería complejo hablar de comunidad y mucho menos de grupo étnico bajo los parámetros desarrollados legislativamente en la Ley 70 de 1993.

\section{Bibliografía}

Bastos, Rafael. A festa da Jaguatirica, uma partitura criticointerpretativa. Florianópolis: Editora Universidade Federal de Santa Catarina, 2013.

56 En: Resolución 027 de 1999, del 14 de enero, por el cual se firma un acta de constitución y se inscribe un Consejo Comunitario Afrodescendiente en el Municipio de Girardota. 
Blacking, John. How musical is man? Washington: University of Washington Press, 1967.

Bourdieu, Pierre. Meditaciones Pascalinas. Barcelona: Anagramas, 1999.

Cuche, Denys. La notion de culture dans les sciencies sociales. París: Repéresedt, 1996.

Corantioquia. El sainete está corrido. Estudio para la postulación como patrimonio cultural inmaterial departamental. Medellín: Corporación Gaia, 2011.

Corantioquia. Hijos de la Rima: una voz bien hablada cuenta la historia del sainete del Consejo Comunitario Afrodescendiente de la Vereda San Andrés. Medellín: Corantioquia, 2011.

Correa, Carlos. «De Hatogrande a Girardota». Tesis de pregrado, Universidad de Antioquia, 2002.

Cuervo, Ximena., y Edwin Arias. «Imágenes Culturales a través del juego escénico: Sainete». Tesis de pregrado, Universidad de Antioquia, 1989.

Domínguez, María. «Versiones, apropiación e intermusicalidad en el Río de la Plata (126).» En ANTROPOLOGIA EM PRIMEIRA $M \tilde{A} O$, editado por Evelyn Schuler Zea, José Antonio Kelly, Rafael Devos, y Scott Head, 3-19. Florianópolis: Universidade Federal de Santa Catarina Programa de Pós-Graduação em Antropologia Social, 2011.

Diccionario de la lengua española. «Romería». Acceso el 10 de junio de 2016, http://dle.rae.es/?id=WeRtrBl

Dowling, John. Sainetes I: Ramón de la Cruz. Madrid: Castalia Editores, 1981.

Foronda, Arnobia. Tradición oral sobre la historia de la vereda San Andrés Girardota- Antioquia. Girardota: Consejo Comunitario de la Vereda San Andrés - Corantioquia, 2002. 
Gilbert, Shirli. «Music as Historical Source: Social History and Musical Texts». International Review of the Aesthetics and Sociology of Music 1, n 36 (2005): 117-134.

Gómez, John., y Jairo Toro Jaramillo. «Vereda de San Andrés Municipio de Girardota, una propuesta de vivienda para una cultura.» Tesis de pregrado, Universidad de Nacional de Colombia, 1997.

Guattari, Félix., y Suely Rolnik. Micropolítica: Cartografías del deseo. Buenos Aires: Tinta Limón, 2013.

Harney, Lucy. "Carnival and Critical Reception in the "Sainete" Tradition». $M L N 117, \mathrm{n}^{\circ}$ 2, (2002): 310-330.

Henao, Sergio. Los Santuarios y las romerías. Monografía histórica sobre peregrinaciones y santuarios en los municipios de Girardota, Angostura, Copacabana, Sabaneta y Guarne. Medellín: Instituto de Cultura y Patrimonio de Antioquia, 2015.

Hernández, Oscar. «Los mitos de la música nacional. Poder y emoción en las músicas populares colombianas 1930-1960». Tesis de doctorado, Pontificia Universidad Javeriana de Bogotá, 2014.

Hobsbawm, Eric. La invención de la tradición. Barcelona: Editorial Crítica, 2002.

Ley 70 de 1993, del 27 de agosto, Por la cual se desarrolla el artículo transitorio 55 de la Constitución Política.

López, Gustavo., Héctor Rendón, y Fred Danilo Palacio. Atardecer en San Andrés. Música tradicional de Girardota, Antioquia, vereda San Andrés. Medellín: Facultad de Artes, Universidad de Antioquia; Ministerio de Cultura; Gobernación de Antioquia; Alcaldía del Municipio de Girardota y Cooperativa Financiera de Antioquia, 2006.

Meneses, Elkin., Ruth Meneses y Mario Sierra. Tierra prolifica Tierra sagrada. Medellín: Instituto para el desarrollo de Antioquia Idea, 2006. 
Merriam, Allan. «Ethnomusicology Revisited». Ethnomusicology 2, $\mathrm{n}^{\circ} 13$ (1969): 213-229.

Merleau-Ponty, Maurice. Fenomenología de la percepción. Barcelona: Ed. Planeta De Agostini, 1993.

Municipio de Girardota. «Fiestas y celebraciones». Acceso el 22 de julio de 2016, http://www.girardota.gov.co/MiMunicipio/ Paginas/Fiestas-y-Celebraciones.aspx.

Resolución 027 de 1999, del 14 de enero, por el cual se firma un acta de constitución y se inscribe un Consejo Comunitario Afrodescendiente en el Municipio de Girardota.

Orlas, Carlos., Juan Ospina, Felipe Ospina, Julián Betancur, y Manuel Hoyos. Identidad y memoria. Rastros de la tradición oral en la Vereda San Andrés. Medellín: Corporación el balcón - Gobernación de Antioquia - Instituto de Patrimonio y Cultura, 2014.

Rodríguez, Jorge. Maizopolis: monografías de los distritos antioqueños. Medellín: El Correo Liberal, 1915.

Shepherd, John. Music as Social Text. Cambridge: Polity Press, 1991.

Wabgou, Maguemati. "Herencia Negroafricana en Colombia». Contra Relatos desde el Sur. Apuntes sobre África y Medio Oriente, $n^{\circ} 9$ (2012): 99-115.

Wainer, Jean. La mundialización de la cultura. Barcelona: Editorial Gedisa S.A., 2000.

\section{Citar este artículo:}

Larraín González, América., y Pedro José Madrid Garcés. «Manifestaciones artísticas y culturales afrocolombianas. Una aproximación al caso de Girardota (Antioquia)». Historia $Y$ MEMORIA, $\mathrm{n}^{\circ} 15$ (2017): 107-135. DOI: https://doi. org/10.19053/20275137.n15.2017.4926 